\title{
Types and Prevalence Of Peer Victimization Among Secondary School Students in Osun State, Nigeria: Implications for Counselling
}

\author{
Ehindero Serifat Adefunke \\ Faculty of education, Obafemi Awolowo University, Nigeria
}

\begin{abstract}
The study investigated the types and prevalence of peer victimization among secondary school students in Osun State. This was with a view to improving peer relationships among secondary school students. Survey research design was adopted for the study. The population for the study consisted of junior secondary school students in Osun State. Multidimensional Peer Victimization Scale was used to elicit information on the types and prevalence of peer victimization. The result showed that four types of peer victimization were experienced by the students and there was high prevalence of peer victimization among school going adolescent. These types were widespread among secondary school students. The study therefore concluded that peer victimization was a recurring problem among secondary school students and could be reduced through appropriate counseling of students. The implications of the findings to counseling services were discussed.
\end{abstract}

\section{Introduction}

Violence cuts across generations, it affects every segment of the society and it is particularly common among school-going adolescents. Peer victimization as an important aspect of school violence which makes the students to be fearful of school and inhibits their learning potentials. It is a serious problem for school age children and for which they receive limited adult help. Researchers have shown that violence is used in response to conflicts and it is common among adolescents [6], [21].Violence in whatever form usually results in problems like student's protest or unrest.

Peer victimization can be seen as the experience among children of being a target of aggressive behaviour of other children who may not be siblings and necessarily age mates [13]. According to [32) the act was described as an unprovoked attack that causes hurt of a psychological, social or physical nature. [25] also described peer victimization as a problem that occurs when a student is exposed repeatedly and overtime to negative actions on the part of one or more other students. It could be deduced from the definitions that peer victimization is not a problem that could be left unsolved.
Therefore urgent attention needs to be focused on this matter.

At times, the perpetrator willfully and unconsciously desires to hurt another student and put $\mathrm{him} /$ her under tension. The tension is caused not only by what actually happens but also by constant fear of what might happen.

Peer victimization can be classified into four types [17). These are physical victimization, verbal victimization, social manipulation and attack on property. Physical victimization is the least sophisticated type of victimization and the bullies are usually well known by the students and staff in school. Their actions include punching, slapping or kicking the victim or damaging the victim's property. Another type, verbal victimization leaves no physical evidence but tears up the victim on the inside. It is the use of words to hurt or embarrass another person. Constant teasing and name calling, reactive victims often go out of their way to instigate the bullies and then claim self-defense when the incident escalates. There is also cyber bullying which can be an extremely vicious form of bullying because the social inhibition of face-to-face confrontation is removed, and the bullying is very public and can occur 24 hours per day (30). An emerging literature indicated that online bullying is a significant issue for a number of youths, with at least certain percentage of those who use the internet reporting being bullied online (12). A study of online harassment (33) provides a profile of youths who bully online, the characteristics and correlates of online bullies are those of traditional bullies; these youths have a history of ineffective or inappropriate parental monitoring and typically have a number of psychosocial challenges. In online bullying, there is no sex difference, male and female do victimize online. However, (33)found that compared with nonbullied youth, youths who are victims of traditional bullies are significantly more likely to bully others online than in person, may be the internet provides socially marginalized children a safe outlet to express retaliation in a way that are not normally accessible to them. These types of peer victimization with their associated behaviours tend to inhibit learning potentials and create interpersonal problems for victims [29).

Many factors could be attributed to the issue of peer victimization. Schools bring together large number of students from different backgrounds. 
These students were reared in a wide range of cultural environments with different models of development. Some children are aggressive probably because they have been unconsciously taught at home by their parents or siblings that intimidating and verbally abusing others are the best means of getting their own way and these sometimes work [10]. In secondary schools peer victimization constitutes a major problem that makes the students fearful of school because of the kind of harassment they experience from their peers. When this kind of problem happens in schools, it impedes the productivity of teachers and students' performance. This problem is fast becoming a normal part of childhood experience which Nigerian children must learn to tolerate as part of the process of growing up [20).However, this hardly recognized as a problem but, because of its possible influence to negate the learning process, it has become a legitimate problem for empirical investigation.

[16] opined that peer victimization in schools is a global problem that can have negative consequences for the general school climate and for the rights of students to learn in a safe and secure environment without fear. However, there is dearth of information on the types and the prevalence of peer victimization among secondary school students in Osun State. Information is also lacking on the most appropriate administrative and counseling strategies required to manage the negative effects of peer victimization.

Research on the prevalence of peer victimization in Nigeria is sparse. Outside Nigeria, a sizeable number of studies have reported prevalence, but in some of the studies, it is difficult to identify the proper contexts within which peer victimization takes place. This is important because there seems to be a relationship between the context and prevalence of peer victimization. The refusal of victims to report cases of victimization for whatever reasons, obscure the frequency and prevalence of peer victimization. In other words, prevalence reported in the existing literature represents estimates. The occurrence of peer victimization is multifaceted and encompasses a number of behaviours, it could be culture, age and so on and as such it is not easy to ascribe a single cause to its occurrence in children (2). The data from Australia mirrors that of other countries such as Canada (27) Scandinavia (23), Ireland (22) and England (5). Recent figures suggested that $50 \%$ of children have experienced being bullied in school at least once (29). It has been estimated that for Australian students (between the ages of 9 and 17), one student in five is bullied at least once a week (29). In other words, $20 \%$ of Australian students get bullied each week and the report indicated that verbal victimization was the most common form of peer victimization.
(24), reported that about $15 \%$ or one out of seven Norwegian primary and high school students was a victim of the phenomenon either as bullied or as victims. Nesbitt (19), reported that 10 percent of students in the United States are victimized by bullies. It was reported that peer victimization is a pervasive phenomenon and (24) found that boys were more often the victims of direct victimization, whereas girls were more often the victims of indirect victimization. Another important point is that most students who are bullied either do not report the bullying to adults or they wait for a very long time before doing so. The reasons for not reporting include feelings of shame, fear of retaliation and fear of being disciplined by parents. (26) reported that the percentage of students who reported being victims of bullying decreases with age. The higher the class level or socio-economic class, the lower the level of victimization. (24), reported that many children are being bullied by older students and this underlies power differentials in bullying. This implies that students of 9-12 years, 12-14 years and in junior classes experiencing high level of victimization than students of above 15 year experiencing low level of victimization.

\section{Purpose of the Study}

The purpose of the study is to determine the types and frequency of peer victimization among secondary school students in Osun State. Specifically, the study sought to identify and describe each type of peer victimization, the factors which inform such violent behaviours and then discuss the relationship between both the types and frequency of peer victimization to the teaching and learning processes in the classroom. An additional objective of the study is to discuss the challenges of peer victimization to counseling services in particular and the society in general.

\section{Theoretical Framework}

The complex nature of aggression and the behaviour associated with it, how this behaviour is learnt and reflected among students in the school learning environment show that one single theory cannot adequately account for a study on aggressive related behaviour and its impacts. Consequently, the theoretical framework for this study is a form of an eclectic theory of aggression which combines the biological and psychological origins of aggression with social learning theory.

According to [4] human beings by their nature are biologically, psychologically and socially prone to aggressive impulses to which they respond. The willingness or not to respond and the appropriateness and the extent of such responses to aggressive impulses are functions of past social learning 
experiences and related environment factors. In this case, a combination of Dollard and Berkowitz concept of aggression and Bandura social learning theory provide the theoretical framework for this study. According to [8),[4] individuals who are frustrated, thwarted, annoyed or threatened will behave aggressively since aggression is a natural, almost automatic response to frustrating circumstances. Aggression is always a consequence of frustration. Atimes, people respond to frustration and anger differently depending on their biological constitution, family background and the impact of social learning. Some do indeed respond with aggression but others display a wide variety of responses. (4) stated that frustration increases the probability that an individual will become angry and act aggressively with an aggression defined as a behavior whose goal is to cause conflict, damage or injury on some objects or person. In short, frustration facilitates the performance of aggressive behavior. An aggressor may be blocked for obtaining an expected goal in which case frustration results, which in turn generates anger. It is the resultant anger which predisposes an individual to behave aggressively whether the person actually engages in aggressive actions will depend in part on his / her learning history, interpretation of the event and individual way of responding to frustration. It also depends however, on the presence of aggression eliciting stimuli in the environment. Perpetrators may probably have history of cumulative social and psychological deprivation of which they respond through victimization.

Another component theory of aggression is Bandura's social learning theory. In this theory, human beings adapt, learn and maintain behaviour patterns that have worked in the past even if they worked occasionally. This learning process begins in early childhood. Children develop many complex behaviour including aggressive ones merely by watching their parents and significant others in their communities and school environment through a process called modeling or observational learning. A child's aggressive behaviour pattern, therefore, is often acquired through the modeling or imitation of other people, real and imagined in the child's environment. Victimization observed among secondary school students is assumed to follow this pattern of behaviour that is learnt from others reinforced or rewarded and practiced on fellow students in schools [3]. According to (3) when a child's initiative behaviour is reinforced or rewarded by praise and encouragement from significant models, the probability that the behaviour will occur in the future is increased. He identifies three major types of models, family members, members of one's subculture and symbolic models provided by the media. It should be noted that family members, particularly parents can be very powerful models until early adolescence. In early adolescence, peer models are likely to dominate. Not surprising, the highest incidence of aggression is found in communities and groups in which aggressive models abound and fighting prowess is regarded as a valued attribute. Also, mass media including television movies, magazines, newspaper and books provide additional symbolic models in victimization and the adoption of coping strategies. Television pervades the life of the growing child even the very young child and offers potentially powerful aggressive and models of victimization. The structure of the family and value system it embraces provides opportunities for children to learn aggressive or anti-social behaviours which are later reflected in the school environment. Hence, social learning theory hypothesizes that the rudiments of victimization behaviour initially acquired by children through observing aggressive models or on the basis of direct experiences are progressively and eventually used to victimized schoolmates. It is however possible that victimization as behaviour is latent in an individual. The social learning system acknowledges that the biological structures and prevailing environmental conditions can set limits on the types of aggressive responses that can be learned. Genetic endowment and a variety of complex counseling strategies may influence the rate and types of individual and coping strategies.

The relevance of these theories to peer victimization is that the aggressive behaviours if not eliminated or modified are carried over to school where they manifested in the form of bullying and other forms of aggression. The original negative interactions in the home contribute to the development of victimization in schools. A child who was nurtured in an aggressive home environment cannot think of other alternatives to solving problems than to fall back on aggression and violence which dominated his/her upbringing. The home environment is therefore critical in children's development and all members of the family especially the parents must show models of good social behaviours for their children to emulate.

The environment in which the child grows and develops produces a range of different models from which the child can adopt. Children learn from television too, parents should try to regulate what children watch on television and the caliber of children they interact with. Modelling techniques have been used to discourage deviant behaviours by exposing subjects to models who would not, no matter the circumstances succumb to temptations. Bandura's social learning theoretical model therefore, provide as a framework to understand how some children acquire aggressive behaviour, how these behaviour, how these behaviours are reinforced by the family factors and school environment and how interactions with school mates facilitate or 
inhibit the aggressive behaviours through adopted coping strategies.

Attention has been recently drawn to Nigerian children who are involved in aggressive behaviour. This behaviour leads to victimization in schools which may eventually result into life problems such as criminality, school dropout, alienation, depression and anxiety (25). In addition, victimization and its related behaviour problems are not only chronic but are often transmitted across generations (13).

\section{Theoretical Framework}

\subsection{Procedure}

Survey research design was used in this study. The population consisted of junior secondary school students in Osun State. The sample consisted of 1500 students selected by stratified random sampling technique using class level (Junior secondary school I-III) as strata. Fifty students were randomly selected in each Junior secondary school, hence a total of 150 students from each of the 10 selected secondary schools. In other words 1,500 students were used in this study. The adapted version of the Multidimensional Peer Victimization Scale was used to collect data for this study. This scale consisted of the items designed to elicit information on the experiences they had of being hurt by their mates or friends in school. Multidimensional Peer Victimization Scale (MPVS) was developed and validated by the [17). The items in the original MPVS were intended to find out the extent to which students were victimized by their peers. The original 16 items by the authors were adapted and validated. Four items were added to the original MPVS to meet the purpose of this study. The items covered four aspects of peer victimization, namely, physical victimization, verbal victimization, social manipulation and attack on property. The instrument was administered to all the students. The students were required to indicate how often they were victimized over a range of $0-2,(0=$ Not at all, $1=$ Once, $2=$ More than once).The items were found to possess satisfactory internal reliability with values of $0.85,0.78,0.77$ and 0.73 for physical, verbal, social victimization and attack on property subscales respectively [17]. Scores of each of the respondents on the total scale have a possible range of $0-40$ and possible range of $0-10$ on each of the four subscales. Scores between 0-18 indicate a low level of victimization, 19-26 indicate moderate level of victimization, while scores between 27-40 showed a high level of victimization. Descriptive statistics were used to analyze and interpret the data obtained in the study.

\subsection{Analysis of Data}

Table 1 summarizes the responses of the students on the types of victimization they have experienced as indicated on the returned questionnaires. The physical victimization (items 1, 5,8,10 and 13) experienced by respondents show that (item 13) was the most frequently used with $72.3 \%$ of the respondents indicating that they have been beating once or more times, This is followed by (item 10) in which $67.3 \%$ of the respondents indicated that they have been injured one or more times, further more, $63.0 \%$ of the respondents indicated to have been pinched.

As shown in table 1 , the social victimization (items 2,6,7,11,14,15,19) experienced by the respondents was led by (item19) in which $76.6 \%$ of the victims indicated that they were made to feel irritated one or more time, more so, $60.6 \%$ and $60.3 \%$ respectively have been made fun of because of their appearance(item 7) and laughed at (item 15). Furthermore, table 1 revealed that verbal victimization (items $3,17,18$ ) frequently takes place among secondary school students as more than $60 \%$ of the respondents indicated to have experienced the items that made up verbal victimization on the Multidimensional Peer Victimization Scale. 75.2\% have experienced being swore at (item 17), 70.4\% have experienced being called names (item 3) and $61.2 \%$ indicated to have experienced being shouted on. It could also be observed in the table that students also experienced attack on property (items $4,9,12,16,20)$. Over seventy-eight per cent of the respondents indicated that other students have once or more stole their things (item 12), this is the highest among the items that made up attack on property as well as the highest among the entire items that up the Multidimensional Peer Victimization Scale.

Table 2: In order to determine whether or not subjects were subjected to specific forms of physical violence within the last one year, their responses to Part Ia of the Multidimensional Peer Victimization Scale were analyzed with emphasis on their gender, age, class and personality.

The analysis shows that more than $50 \%$ of the respondents have experienced one form of victimization or the other in the last one year. When one considers the gender and the rate of peer victimization in the study it could be observed that only $39.4 \%$ and $40.1 \%$ of male and female respectively have not been hurt or experienced pain as a result of what other students did to them. Also, considering the rate of victimization across student's age, it is revealed that $39.1 \%$ and $37.8 \%$ of students within the age bracket of 9-12 and 13-14years have not been hurt or experienced pain from their fellow students. The students who are above 14years even though more matured still experienced victimization 
from their fellow students. Only $41.7 \%$ of the subjects that have not been hurt or experience pains in the last one year from their fellow students. While considering the rate of peer victimization across student's class and personality , table 1 revealed that apart from the introverts with $51.4 \%$ who indicated

Table 1. Types of Peer Victimization among secondary school students

\begin{tabular}{|c|c|c|c|c|c|c|c|c|c|}
\hline \multirow[t]{2}{*}{$\mathrm{S} / \mathrm{N}$} & \multirow[t]{2}{*}{ Items } & \multicolumn{2}{|c|}{$\begin{array}{l}\text { Not at } \\
\text { all }\end{array}$} & \multicolumn{2}{|c|}{ Once } & \multicolumn{2}{|c|}{$\begin{array}{l}\text { More than } \\
\text { once }\end{array}$} & \multicolumn{2}{|c|}{ Undecided } \\
\hline & & No & $\%$ & No & $\%$ & No & $\%$ & No & $\%$ \\
\hline 1. & Pinched me & 515 & 36 & 324 & 22.5 & 580 & 40.5 & 12 & .8 \\
\hline 2. & $\begin{array}{l}\text { Tried to get me into trouble with } \\
\text { my friends. }\end{array}$ & 562 & 39.3 & 398 & 27.8 & 447 & 31.2 & 24 & 1.7 \\
\hline 3. & Called me names & 387 & 27.0 & 319 & 22.3 & 689 & 48.1 & 36 & 2.5 \\
\hline 4. & $\begin{array}{l}\text { Took something of mine without } \\
\text { permission }\end{array}$ & 481 & 33.6 & 402 & 28.1 & 548 & 38.3 & 0 & 0 \\
\hline 5 & Kicked me & 550 & 38.4 & 511 & 35.7 & 358 & 25.0 & 12 & .8 \\
\hline 6. & Turned my friends against me. & 581 & 40.6 & 305 & 21.3 & 507 & 35.4 & 38 & 2.7 \\
\hline 7. & $\begin{array}{l}\text { Made fun of me because of my } \\
\text { appearance. }\end{array}$ & 528 & 36.9 & 307 & 21.5 & 560 & 39.1 & 36 & 2.5 \\
\hline 8. & Slapped me. & 690 & 48.2 & 355 & 24.8 & 386 & 27.0 & 0 & 0 \\
\hline 9. & Tried to break my things. & 620 & 43.3 & 573 & 40.0 & 238 & 16.6 & 0 & 0 \\
\hline 10. & Injured me physically & 468 & 32.7 & 540 & 37.7 & 423 & 29.6 & 0 & 0 \\
\hline 11. & Refused to talk to me. & 891 & 62.3 & 195 & 13.6 & 295 & 20.6 & 50 & 3.5 \\
\hline 12. & Stole something from. & 293 & 20.5 & 394 & 27.5 & 732 & 51.2 & 12 & .8 \\
\hline 13. & Beat me. & 383 & 26.8 & 319 & 22.3 & 729 & 50.0 & 0 & 0 \\
\hline 14. & $\begin{array}{l}\text { Made other people not to talk to } \\
\text { me. }\end{array}$ & 680 & 47.5 & 393 & 27.5 & 358 & 25.0 & 0 & 0 \\
\hline 15. & Laughed at me. & 568 & 39.7 & 335 & 23.4 & 528 & 36.9 & 0 & 0 \\
\hline 16. & $\begin{array}{lll}\begin{array}{l}\text { Deliberately } \\
\text { property. }\end{array} & \text { damaged } & \text { my } \\
\end{array}$ & 791 & 55.3 & 384 & 26.8 & 208 & 14.5 & 48 & 3.4 \\
\hline 17. & Swore at me. & 319 & 22.3 & 290 & 20.3 & 786 & 54.9 & 36 & 2.5 \\
\hline 18. & Shouted on me. & 532 & 37.2 & 455 & 31.8 & 420 & 29.4 & 24 & 1.7 \\
\hline 19. & Made me feel irritated. & 311 & 21.7 & 437 & 30.5 & 659 & 46.1 & 24 & 1.7 \\
\hline 20. & Hijacked my properties. & 441 & 31.1 & 350 & 24.7 & 616 & 43.4 & 12 & .8 \\
\hline
\end{tabular}


Table 2. Prevalence of Peer Victimization among secondary school students

\begin{tabular}{|c|c|c|c|c|c|}
\hline \multirow{2}{*}{\multicolumn{2}{|c|}{ Variables }} & \multicolumn{3}{|c|}{ Have you been victimized in the last one year? } & \multirow[t]{2}{*}{ Total } \\
\hline & & Yes & No & Undecided & \\
\hline Gender & $\begin{array}{l}\text { Male } \\
\text { Female }\end{array}$ & $\begin{array}{l}341(59.7) \\
506(58.8)\end{array}$ & $\begin{array}{l}225(39.4) \\
345(40.1)\end{array}$ & $\begin{array}{l}5(0.9) \\
9(1.0)\end{array}$ & $\begin{array}{l}571(39.9) \\
860(60.1)\end{array}$ \\
\hline Age & $\begin{array}{l}\text { 9-12yrs } \\
\text { 13-14yrs } \\
\text { Above 14yrs }\end{array}$ & $\begin{array}{l}235 \text { (60.9) } \\
261(61.3) \\
351(56.7)\end{array}$ & $\begin{array}{ll}151 & (39.1) \\
161 & (37.8) \\
258 & (41.7)\end{array}$ & $\begin{array}{l}0 \\
0 \\
10(1.7)\end{array}$ & $\begin{array}{l}386(27.0) \\
426(29.8) \\
619(43.2)\end{array}$ \\
\hline Class & $\begin{array}{l}\text { JSS1 } \\
\text { JSSII } \\
\text { JSSIII }\end{array}$ & $\begin{array}{l}366(61.4) \\
275(57.9) \\
206(57.2)\end{array}$ & $\begin{array}{l}226(37.9) \\
191(40.2) \\
153(42.5)\end{array}$ & $\begin{array}{l}4(0.7) \\
9(1.9) \\
1(0.3)\end{array}$ & $\begin{array}{l}596(41.6) \\
475(33.2) \\
360(25.2)\end{array}$ \\
\hline Personality & $\begin{array}{l}\text { Extroversion } \\
\text { Introversion }\end{array}$ & $\begin{array}{l}824(59.4) \\
17(48.6)\end{array}$ & $\begin{array}{l}552(39.6) \\
18(51.4)\end{array}$ & $\begin{array}{l}14(1.0) \\
0\end{array}$ & $\begin{array}{ll}1394 & (97.6) \\
35 & (2.4)\end{array}$ \\
\hline
\end{tabular}

not to have been hurt or experienced pains from fellow students more than $50 \%$ of the respondents across class and personality have been hurt or have experienced pains from fellow students. Therefore, the result showed that the rate of peer victimization among secondary school students in Osun State is high.

The findings of this study indicate that there were at least four types of peer victimization among secondary school students in Osun State. These are physical victimization, social manipulation, verbal victimization and attack on property. These types coincide with the items in Multidimensional Peer Victimization Scale developed by (17). It was shown that physical victimization is the most frequently used with respondents indicating that they have been physically victimized once or more followed by social manipulation, they're being socially victimized, this showed that the students were being made fun of, maybe because of their appearance or something else, being laughed at or being made to feel irritated. These reactions can make victims of peer victimization to be fearful of school because school environment is no more conductive and this can make the victims to become truants. Also, verbal victimization takes place as larger percentage of the students have experience being victimized once or more. It was revealed also that attack on property was frequent. The number of students reported being physically, socially, verbally victimized and attack on property appeared disturbing as it suggests the existence of a serious problem that may have long term effect on student's emotional and social development and impact negatively on the social and psychological well being of the entire society.

It was observed that peer victimization may probably be transforming normal students into truants and making them in the process be fearful of school thus affecting school attendance and performance. One can assume that the exposure of young school students to victimization is likely to result in a high level of social aggression which according to (11) may persist into adulthood in the form of criminality, marital violence, child abuse and sexual harassment and even terrorism. The effect of peer victimization will not affect the school children alone but may likely extend to the family members, community members and the whole nation. It may also affect the school and classroom environment and prevented the students from learning to the best of their ability (14). Peer victimization has implications for academic success which is associated with poor performance, disliking school and absenteeism. It has been reported that youths who had been victimized as children or adolescents are more likely to develop increased rate of violence related behaviours than others. (14), also reported that violence in and among youth is a continuum that has bullying behaviour such as fighting and teasing at one end of its continuum.

It was shown that the rate of peer victimization is high among the students and the rate at which these students were being victimized is educationally worrisome as it suggests the existence of a serious problem that is likely to have short and long term effects on the student's emotional and social 
development, and by logical extension impact negatively on the social and psychological wellbeing of the students. According to the information on table 2 more than half of the respondents had been victimized more than once by the perpetrators of peer victimization. There was no evidence that the victims had previously offended the perpetrators. Eventually, the consequences impact negatively on the learning processand academic performance of the students through their experiences. . Students who are victims of peer victimization are likely to experience problems such as depression, anxiety and low self-esteem (1); (7); (31). It also appears reasonable to conclude that the high level of peer victimization reported by respondents is probably one of the early signs of anti-social behaviours that eventually results in youth violence and violent crimes in Nigeria society (28).Peer victimization is a serious issue that requires the immediate attention of school authorities at local, state and national levels as the phenomenon affects the academic ability of the students. It is possible that school administrators are unaware of the magnitude of this problem in the school. If unchecked, the different forms of victimizations can graduate to more serious forms of aggression and violence including cultism thus providing a fertile ground for breeding cultists among students in secondary schools. The implications of such on teaching, learning and general administration of the school can only be imagined. Peer victimization can prevent the implementation of many development programme which require the inputs and participation of normal and enthusiastic young Nigerians.

\section{Implications for Counselling}

Shortage of qualified counselors in schools will not allow the perpetrators and the victims to have the opportunity of being counseled on the problem of victimization. There is also need for sufficient funds to establish and equip Counseling Units in secondary schools and provide counseling facilities in the school to render effective counseling services. In a clear recognition of the critical value of counseling services and shortage of qualified counselors in the secondary school the (18) states that;

In view of the apparent ignorance of many young people about career prospects and in view of personality maladjustment among school children counselors shall be appointed in post-primary institutions --------

qualified personnel in this category are scarce p.53.

The acute shortage of such qualified counselors in the secondary schools and scarcity of such Units is itself a key factor in promoting victimization related violence among secondary school children. The prevalence of peer victimization in schools seems to be the logical consequence of both the shortage of personnel and the scarcity of counseling services. These factors in addition to the shortage of funds and lack of encouragement from the school authority seem to compound the problems of providing quality counseling services in the secondary schools. In order to intervene positively and eradicate the different forms and high prevalence of peer victimization in secondary school, State governments should be encouraged to implement the provision of the (18) section ii (j) by establishing /restoring counseling services and employing qualified counselors to provide qualify counseling services. Also, schools should investigate and understand more of the factors in the home and school environments which promote peer victimization in schools. It is necessary to understand different patterns of child rearing and their possible impacts on peer victimization. Such an understanding will suggest the most effective means of intervention. It has been shown for example that frequent whipping may arouse violent behavior from the child (15). Idleness among students have been attributed to peer victimization that is, lack of productive activities both at home and school give opportunity for students to engage in peer victimization, students should be usefully engaged ,for example, by assigning them work to be done. Classroom teachers should encourage collaborative academic work among the students so as to develop healthy interpersonal relationships that tend to discourage any form of peer victimization.

An aggressive awareness and sensitization campaign should also be undertaken by state Ministries of Education through available counseling units and relevant Non- Governmental Organization to highlight the negative impacts of peer victimization among students. Under the awareness campaign, victims of peer victimization should be encouraged to report all cases of actual and potential victimization to appropriate school authorities. There is no doubt the urgent need to begin to re-emphasize the educational and moral values of counseling services and the training of counselors focusing on the increasing ramifications and potential negative impacts of peer victimization. Terrorism and related forms of violence may in fact be rooted in the inability of counsellor to adequately curtail the different forms of peer victimization at secondary school level.

\section{References}

[1] Austin, S., \& Joseph, S., (1996). Assessment of bully/victim problems in 8-11year old. British Journal of Educational Research, 92, 86-99.

[2] Balogun, S. K., Olapegba, P.O. \& Opayemi, A.S. (2006). Influence of Gender, Age, Religion and Ethinicity 
on Peer Victimization among primary four pupils in Ibadan . Nigeria. Kamla-Raj. Pp 109-111.

[3] Bandura, A., (1977). Social Learning Theory. Englewood Cliffs, N.J. Prentice Hall.

[4] Berkowitz, L., (1963). Aggression: A social psychological Analysis. New York, NY, McGraw Hill.

[5] Boulton, M.J. \& Underwood, K. (1992). Bully/victim problems among middle school Children. British Journal of Educational Psychology, 62, 73-87.

[6] Coloroso, B. (2002). The bully, the bullied and the bystander: Breaking the cycle of violence, http://www.ctvnews.com/content/publish/poups/tagged/arti cles/coloroso.htm.

[7] Craig, W.M. (1998). The relationship among bullying, victimization, depression, anxiety and aggression in elementary school children. Personality and individual Differences. 24,123-130.

[8] Dollard, J., Doob, L.W., Miller, N.E., Mowrer, O.H. and Sears, R.R. (1939). Frustration and Aggression. New Haren CT.Yale University Press.

[9] Ehindero, O.J. (1994). School and Curriculum Evolution in Nigerian Schools. Text-flow, Ibadan.

[10] Erinne, L.A. (2005).Sunday Comet, May 15. pp 17.

[11] Farrington, D.P. (1993). Understanding and preventing victimization. In M. Tonry \& Morris (Eds.), Crime and Justice: An Annual Review of Research (Vol. 17). Chicago: University of Chicago Press.

[12] Finkelhor, D. (1995). The victimization of children: A developmental perspective, American Journal of Orthopsychiatry, 65, 177-193.

[13] Hawker, D.S.J. \& Boulton, M.J. (2000). Twenty years research on peer victimization and psychosocial maladjustment: A meta-analytic review of cross sectional studies. Journal of Child Psychology and Psychiatry 41 (4): 441-455

[14] Hazler, R., Hoover, J. \& Oliver, R. (1992). 'What Kids Say About Victimization." The Executive Educator, $14,20-22$.

[15] McManus, M. (1995). Troublesome Behaviour in the Classroom. 2nd edition. London: Routledge.

[16] Morrison, B. (2002). Restorative Justice and School Violence: Building Theory and Practice. In Debarbieux and C.Blaya (Eds), Violence in schools and public Policies. Youth Violence and Social Exclusion Series. Elsevier, Paris.

[17] Mynard, H., \& Joseph, S. (2000). Development of the Multidimensional Peer Victimization Scale. Aggressive Behaviour, 26, 169-178.

[18] National Policy on Education, (2004). Federal Government Press, Lagos.
[19] Nesbit, W.C. (1999). Black eyes bruised souls: A portrait of victimization. St. John's, NF: Council for Exceptional Children/ Memorial University.

[20] Obidi, S.S. (1990). Indigenous moral education of the Yoruba in Nigeria. Nigerian Journal of Educational Foundation, 1, 29-44.

[21] O’Connell, P; Pepler, D. and Craig, W. (1999). Peer involvement in victimization: Insights and challenges of intervention. Journal of Adolescence, 22: 437-452.

[22] O’Moore, A.M. (1986). Bullying in Britain and Ireland: An Overview. In E. Roland and E. Munthe (eds.). Bullying, an International Perspective. London, Fulton.

[23] Olweus, D. (1991). Bully/ Victim problems among social based intervention program. The Development and Treatment of Childhood Aggression. D. Pepler and K. Rubin (Eds.). Erlbaum, Hillsdale, NJ.

[24] Olweus, D. (1993). Victimization at School. Cambridge, M.A: Blackwell.

[25] Olweus, D. (1994). Victimization at school Long term Outcomes for the Victims and effective School Based Intervention Program. (L. Rowell Huesmann). Plenum Press, New York.

[26] Olweus, D. (1997).Bully/ Victim problems in School: Knowledge base and an effective intervention programme, Irish Journal of Psychology, 18(2), 170-190.

[27] Pepler, D.G., Craig, W.M., Ziegler, S., \& Charach, A. (1997). An evaluation of an anti-victimization intervention in Toronto Schools. Canadian Journal of Community Mental Health, 13, 95-110.

[28] Popoola, B.I. (2005).Prevalence of peer victimization among secondary school students in Nigeria. International Education Journal, 6(5) 508-516.

[29] Rigby, K. (1996). Victimization in schools and what to do about it. Melbourne: The Educational Research.

[30] Selekman, J., and Vessey, J.A. (2004). Bullying. It isn't what it used to be. Pediatric Nursing, 30(3), 246-249.

[31] Stanley, L. \& Arora, T.C.M.J. (1998). Social exclusion among girls. Their self-esteem and coping strategies. Educational Psychology in Practice. 14, 94-100.

[32] Smith, P.K (2000). Victimization and harassment in Schools and the rights of Children and society, 14:294303.

[33] Ybarra, M.L., \& Mitchell, K.J.(2004). Youth engaging in online harassment: For Juvenile Crimes, January 1, 1973- September 30, 2004. Retrieved from www.law.onu.edu/faculty/streib 